\title{
ETHICAL CHALLENGES IN THE CONSERVATION OF THE WALL PAINTINGS OF CHAPEL 11 AT THE SACR0 MONTE DI VARALLO
}

\section{PIQUÉ Francesca ${ }^{1}$ JEAN Giacinta ${ }^{2}$}

1 SUPSI Scuola universitaria professionale della Svizzera italiana (University of Applied Arts and Sciences of Souther Switzerland), Dipartimento ambiente costruzioni e design, Istituto Materiali e Costruzioni, Campus Trevano, 6952 Canobbio, Switzerland https://orcid.org/0000-0002-3351-7087

2 SUPSI Scuola universitaria professionale della Svizzera italiana (University of Applied Arts and Sciences of Souther Switzerland), Dipartimento ambiente costruzioni e design, Istituto Materiali e Costruzioni, Campus Trevano, 6952 Canobbio, Switzerland https://orcid.org/0000-0001-7397-2589

ABSTRACT: Chapel 11 is one of the 45 chapels of the Sacro Monte di Varallo. It is decorated with 16th century polychrome terracotta statues and wall paintings representing the Massacre of the Innocents. Since 2015, the University of Applied Sciences and Arts of Southern Switzerland (SUPSI) is in charge of its conservation. Up-close examination of the wall paintings allowed to observe the presence of overpainting, which were evaluated to have no aesthetical and/or technical quality. During the study phase and with preliminary tests for treatment development, it became clear that the removal of this overpaint was risky for the underlying original decoration. Moreover, it was not possible to determine if under the overpainting there was the original layer and in what condition it was. Although IR Reflectography showed the presence of underdrawings, this information did not always coincided with the presence of a paint layer. Considering that the overpainting covers about $80 \%$ of the surface, SUPSI strongly advised against embarking on its removal. This conclusion was achieved after several removal attempts and through regular communication meeting with the stakeholders aimed at illustrating the situation and the results achieved. SUPSI considered more ethical to focus on the development of a ,reversible' stabilization intervention considering that in the future new technologies (to assess the presence of paintings below and to remove overpainting) could make the recovery of what remains of the original decoration easier.

This paper describes the project in terms of the ethical challenges faced when conflicting expectations about the project arised.

KEYWORDS: Sacro Monte Varallo, overpaint, uncovering, ethical challenges, values 


\section{Introduction}

During the conservation project of the wall paintings of the Chapel 11 at the Sacro Monte di Varallo, many issues related to conflicting values impeded to reach an agreed decision about the conservation approach to be adopted. It was difficult to find a rationale compromise that could be shared by all the project stakeholders about the removal of the $20^{\text {th }}$ century overpaints, which cover extensively the wall surfaces. ${ }^{1}$

Varallo is located in North-West Italy and in 2003, together with other eight Sacri Monti, has being recognized from UNESCO as a world heritage site (Fig. 1). ${ }^{2}$ In the form of a small citadel, built on the top of a hill and integrated into a beautiful natural landscape, it is composed by 45 chapels, as individual blocks or groups, a basilica and other buildings forming suggestive architectural spaces. The chapels are dedicated to representing - like in a living theater, with life size sculptures surrounded by scenographic wall paintings - different episodes of the life, passion and death of Jesus, from the Annunciation to the Crucifixion. The visitors see these scenes through a wooden or a metal grate (Fig. 2), filtering the vividness of the representation and inviting them to look carefully inside to catch the dynamic of the event (De Filippis, 2009). ${ }^{3}$

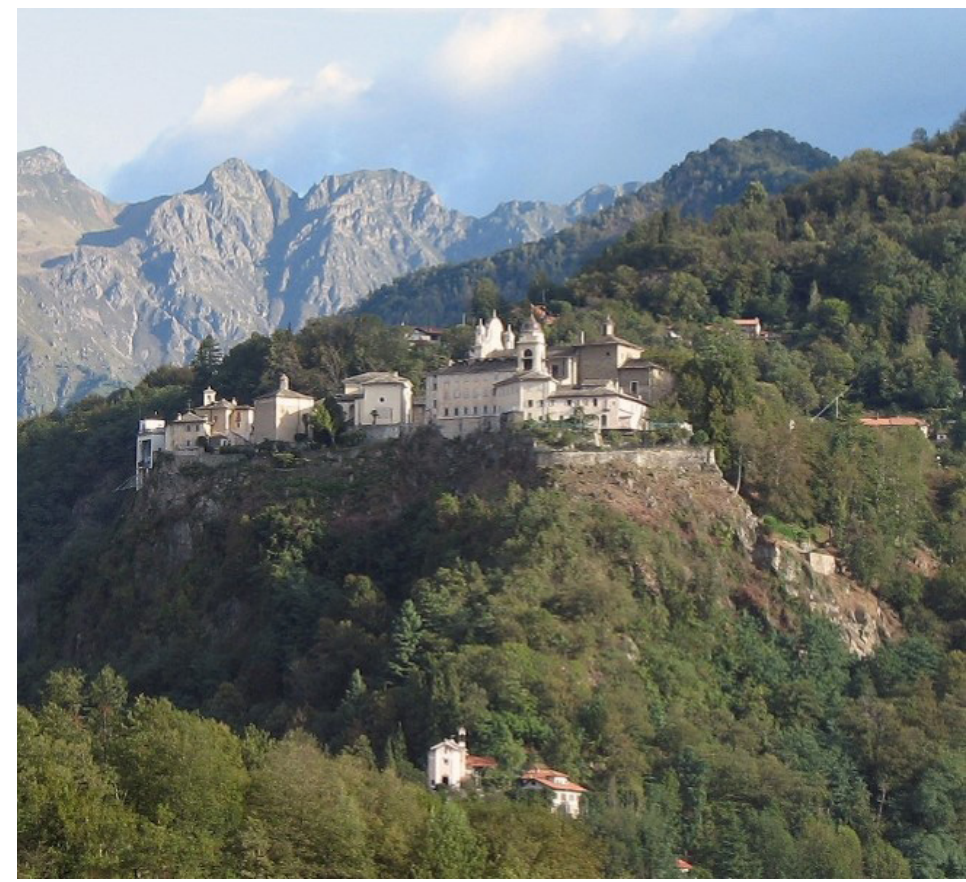

Fig. 1 View of the Sacro Monte di Varallo. Varallo is located in North-West Italy and in 2003, together with other eight Sacri Monti, has being recognized from UNESCO as a world heritage site

1 The definition of overpaint in EwaGlos: "Overpaint: a painting layer which partially or completely covers the original painting layers of an art work”. (Weyer et al. Eds., 2016, p.176). In our case these added layers also cover areas without original paint.

See: https://whc.unesco.org/en/list/1068.

3 See also: http://www.sacromontedivarallo.org/wp/. 
The Sacro Monte was founded by the friar Bernardino Caimi in 1480, to re-create a site where the pilgrims could become part of these episodes with a strong emotional and educational objective. Varallo became a model for the other Sacri Monti that followed. Here between the $16^{\text {th }}$ and $17^{\text {th }}$ century, the most prominent artists of Northern Italy, painters and sculptors like Gaudenzio Ferrari, Bernardino Lanino, Galeazzo Alessi, Tanzio da Varallo, the Fiammenghini, and the Morazzone, were involved in the decoration of the chapels, leaving extraordinary examples of their work, now constituting a unique cultural heritage.

\section{Context}

The SUPSI (University of Applied Sciences and Arts of Southern Switzerland), with its master's degree in conservation-restoration, was engaged in the conservation of the Sacro Monte since 2012. The university, supported by the Isabel und Balz Baechi Foundation, conducted a conservation project for chapel 12 The Baptism of Christ and then for chapel 41 The Deposition of Christ in the Shroud. All these conservation-restoration interventions have been developed as part of the university education activities with the students of the last year of the Master program in conservation of wall paintings. In 2015, the Isabel und Balz Baechi Foundation proposed to engage in a larger project, promoting the conservation of one of the most prominent and large chapels of the site: The Massacre of the Innocents. This is one of the isolated chapels surrounded by trees, with a floor plan measuring six meters by seven and it its eleven meters high. It contains 71 terracotta statues that continue three-dimensionally the scenes depicted on the walls, enhancing the realism of the representation (Fig. 2 and Fig. 3).

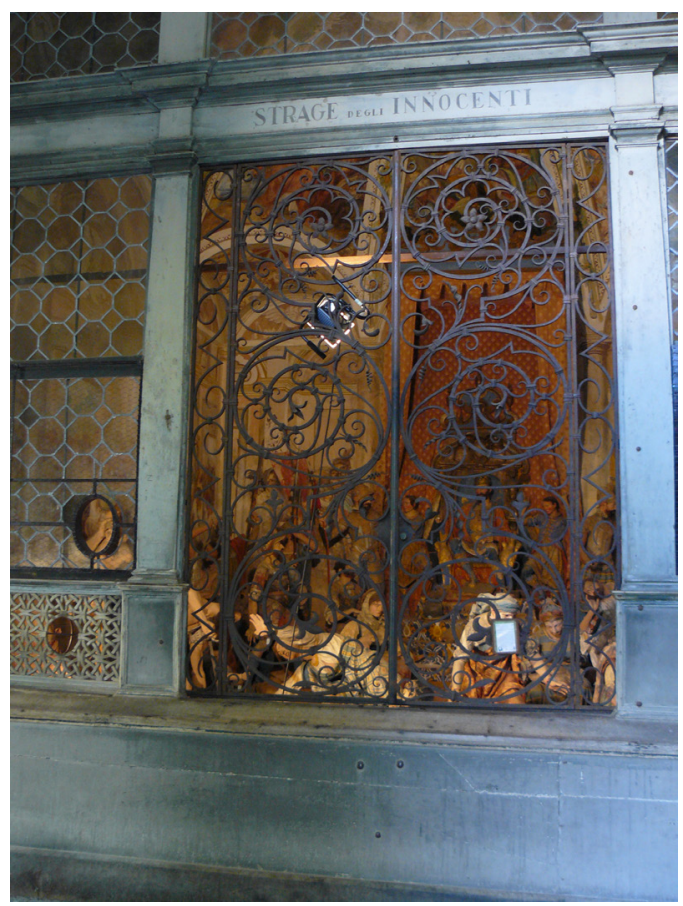

Fig. 2 View of Chapel 11 representing the Massacre of the Innocents. Visitors and pilgrims can see the chapel only through this metal grate 
This chapel was built on an initial project by Galeazzo Alessi (Book of Mysteries 1565-1569) under the patronage of the Duke of Savoy Carlo Emanuele I. The construction began in 1586 with the supervision of the brothers d'Enrico from Alagna (a nearby village). The walls were painted in 1590 by Giovanni Battista della Rovere and his younger brother Giovanni Mauro (better known as the Fiamminghini brothers). They were talented and requested painters, very active between the $16^{\text {th }}$ and $17^{\text {th }}$ centuries, authors of decorating cycles in several important churches in the north of Italy and many chapels of the Sacro Monte in Orta. ${ }^{4}$ The terracotta statues were made in 1591 by Michelangelo Prestinari, an artist working at the Cathedral in Milan. ${ }^{5}$

Three years after completion, the Bishop Carlo Bascapé asked the same sculptor, to add 30 statues of massacred children and to modify the throne of Herod (Fig. 3).

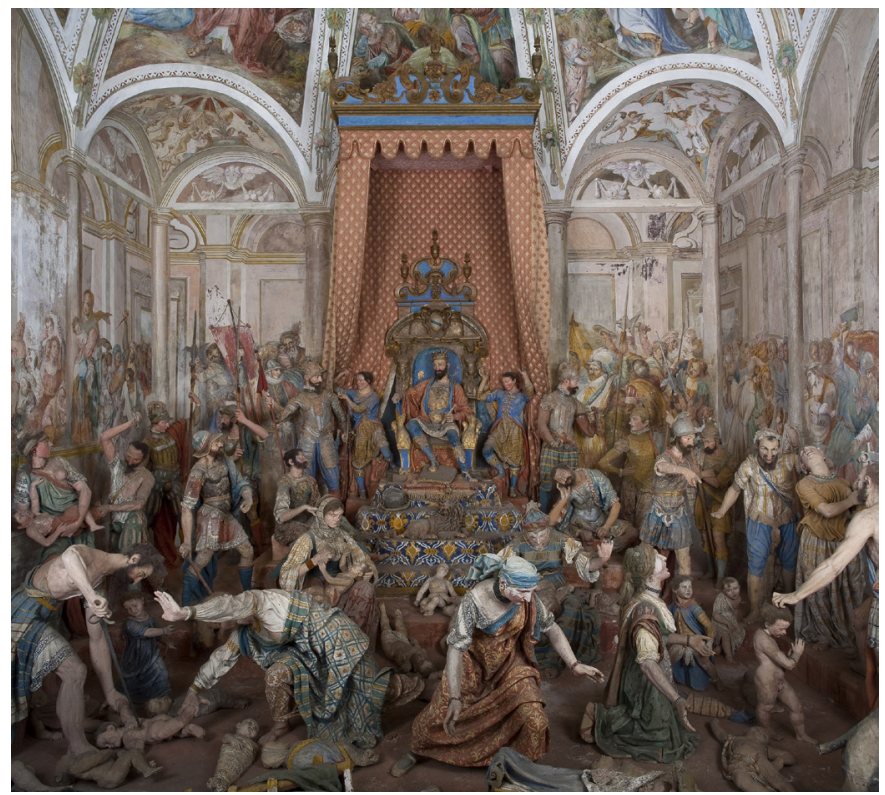

Fig. 3 View of interior of Chapel 11

The project for the conservation of Chapel 11 was developed and implemented following a methodological approach that is extremely important, considering that this was also a practical fieldwork education for the students in conservation. The conservation process starts with understanding the significance of the chapel in its different aspects and gathering all the information necessary to assess its condition conducting visual and scientific investigations. It then proceeds with establishing a concept for the conservation discussing treatment options. The implementation of the intervention, as part of an entire conservation process, allows to define a post-treatment monitoring and maintenance plan, required to prolong the results of the conservation intervention (Burra Charter, 2013; Piqué, 2010).

The assessment phase is fundamental and, considering the dimension and the heterogeneity of the

4 On Giovanni Battista and Giovan Mauro Della Rovere see: Caviglioli,1989.

5 See: Agosti, G. \& Stoppa, J. (Eds.), 2017, pp. 10-11, note 9. 
materials of this works of art, it took an entire year to study the decorations, understanding the conservation problems and their activation mechanism.

The stakeholders involved were, as for the other works in Varallo, the Municipality as formal owner of the site, the Ente di gestione dei Sacri Monti responsible for the managing of the site -in the person of its director- and the local Soprintendenza, responsible for the supervision of the works and for approving conservation decisions. The steering committee was composed by Elena De Filippis, director of the Ente di Gestione, an art-historian involved for several decades in the study and in the conservation of the site, and a conservator-restorer from the Soprintendenza, Emanuela Ozino Caligaris as technical supervisor. From SUPSI the project was coordinated by the authors: prof. Giacinta Jean, architect and responsible for the conservation-restoration study program and by prof. Francesca Piqué, conservation scientist, responsible for establishing the technical and scientific decisions.

\section{Gathering information}

All the written documentary sources were collected by Elena De Filippis, who consulted printed and archival information (documents, photographs and prints), giving an important background about the execution of the decoration and the physical history of the chapel. SUPSI conservation team studied the material and the condition of the statues and of the wall paintings. Visual examination confirmed that over the centuries all the decorations have been extensively repainted on several occasions. Just few of these interventions were documented, not even the last one which was done by the painter Emilio Contini in 1955, after his retirement as director of the Sacro Monte (Fig. 4).

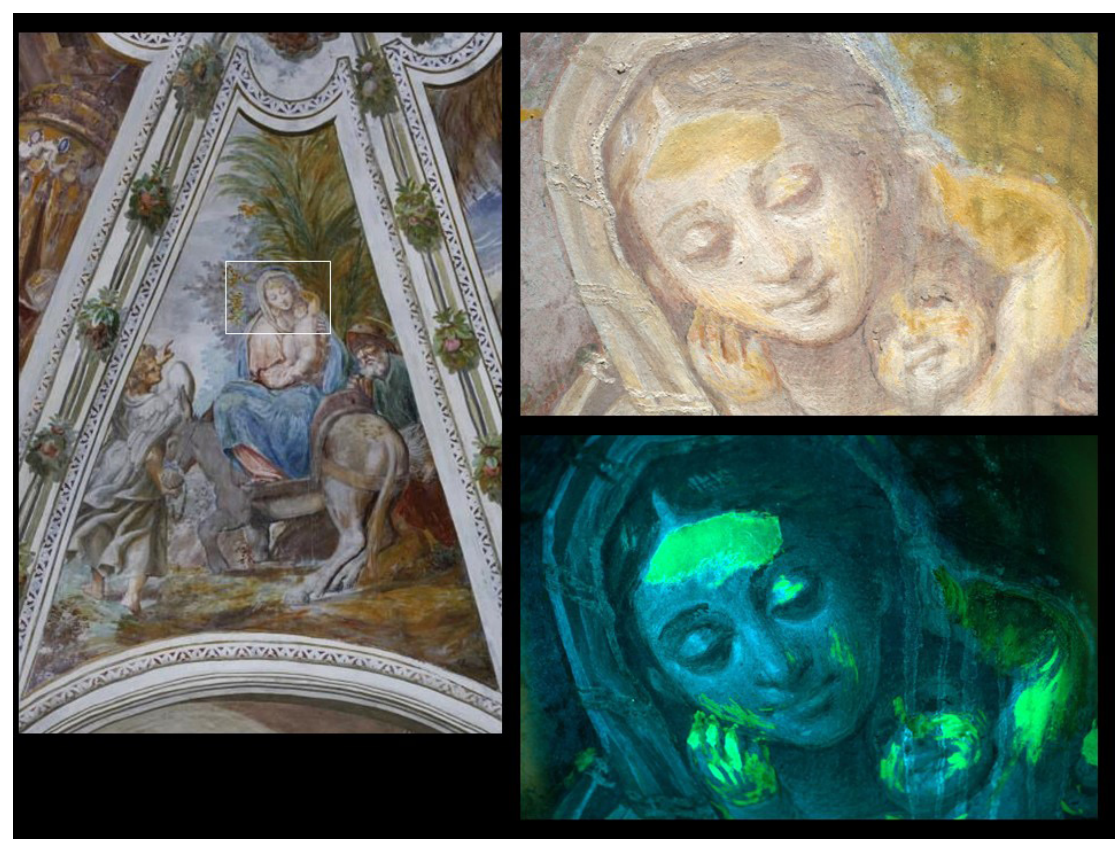

Fig. 4 Portion of wall paintings in the vault of Chapel 11 photographed in visible and UV light. From the scaffolding the heavy and extensive overpainting is clearly visible particularly in UV light due to the high UV induced fluorescence of some of the paint components 
Only few areas with the original paintings by the Fiamminghini brothers remain. They are realized with a mixed technique with portions applied a fresco and/or with lime binder (typically the architectural background) and portions painted a secco with an organic binder for the application of $\mathrm{pH}$-sensitive pigments, such as azurite and malachite, and for metallic layers, e.g. for gilding. The organic binder was studied by FTIR and found to have a lipidic composition. On the statues the layers are applied with lipidic binder on the porous terracotta, previously primed with oil and a lead pigment, probably lead white, added as a siccative. (Piqué et al., 2016)

The $16^{\text {th }}$ century wall paintings - with their delicate surface due to the original technique- are very fragile. The overpainting, done directly on the original surface, in many areas damaged the weak finishing layer, mixing its powdering pigments with the new paint. Both original and overpainting had several conservation problems such as paint flaking, plaster powdering and delamination, and significant surface accumulation of dust. In some areas the overpainting were flaking and detaching from the support, pulling the original layer.

The agents and mechanism of deterioration are closely linked to the semiconfined environment affecting both the statues and the wall painting. Environmental monitoring showed that the daily and seasonal changes of the outdoor air temperature and relative humidity directly influence the interior parameters. In addition, the chapel had suffered by roof water infiltrations, particularly on the north wall, by the typical problems related to the presence of soluble hygroscopic salts, and by small animals nesting inside that chapel.

Beside the conservation problems, an important issue was the presence of the different overpaints covering the walls and the statues. Because of the easy access, the statues were cleaned and retouched on a regular basis and now practically no original paint remains underneath, due to the practice of carefully scraping, performed before the application of new colored layers. On the wall paintings, more difficult to reach, it was possible to recognize at least two major interventions, one carried out in the second half of the $19^{\text {th }}$ century in order to stabiles the surface and one in 1955.

The desire to recover the original Fiamminghini paints, improving the aesthetic aspect of the wall paintings, was an expectation for some of the stakeholders.

In order to take the decision to perform this invasive and irreversible intervention on the walls it was necessary to determine:

1. the extension of the original areas (both visible and covered);

2. the extension of the overpaints and their significance;

3. the technical possibility of removing the overpainting and retrieving the original layers without damaging it. This also allows to understand the condition of the underlying layers.

\section{The extension of the original areas (both visible and covered)}

The conservation team examined the entire surface with different illumination (visible, incident and racking, and UV light) to determine the extension of the surviving original paint. This was a difficult task considering that over $80 \%$ of the surface was covered by overpainting which was often heavy and thick (Fig. 5). 

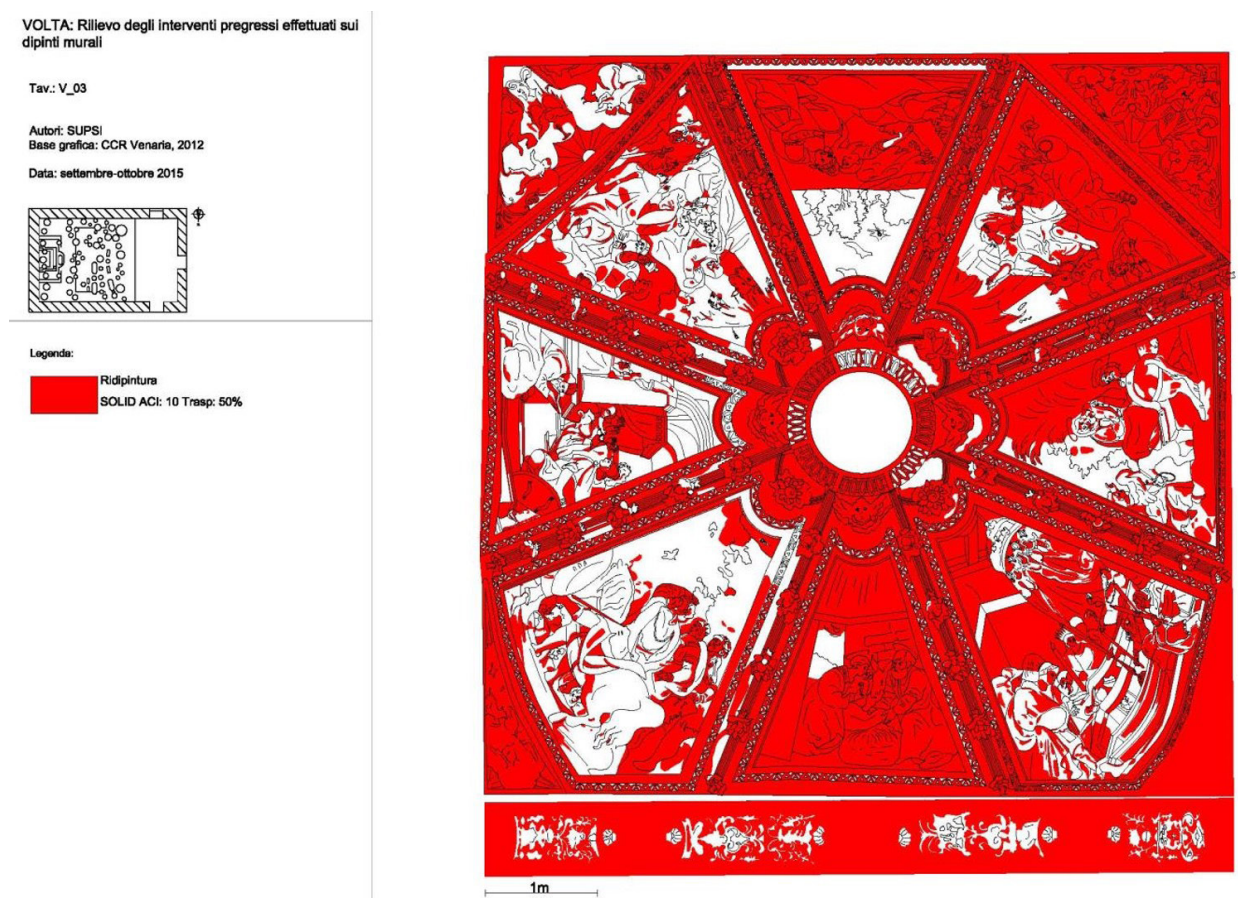

Fig. 5 Visual examination showed that over $80 \%$ of the surface was covered by overpainting which was often heavy and thick and is indicated in red in this map

It was not always possible to understand in which areas the heavy overpaints were covering the original layer. In racking light, the team could distinguish between flat surface and irregular/abraded plaster. In the abraded areas it was logical to suppose that the visible paint was filling areas of loss. Investigations with IR reflectography would show the presence of underdrawing but this could not confirm the presence of paint layers. It became clear that the only mean to determine if there were original painting was to remove the overpainting. The conservators carried out several uncovering tests to determine both if there was an original layer and if it would be possible to safely retrieve it. The 'promising' test areas were selected based on historical photographs taken before the intervention of Contini in 1955, showing good conservation condition of the decoration. In some of these areas, it was possible to rediscover lost details but in others only large losses were revealed (Figs. 6 and 7). In addition, the removal tests disclosed the difference between the original colour scheme and the current one (visible also in cross-section). This was especially noticeable in the architectural background were the original paint had ice gray cold tones while the overpaint had a much warmer one. 


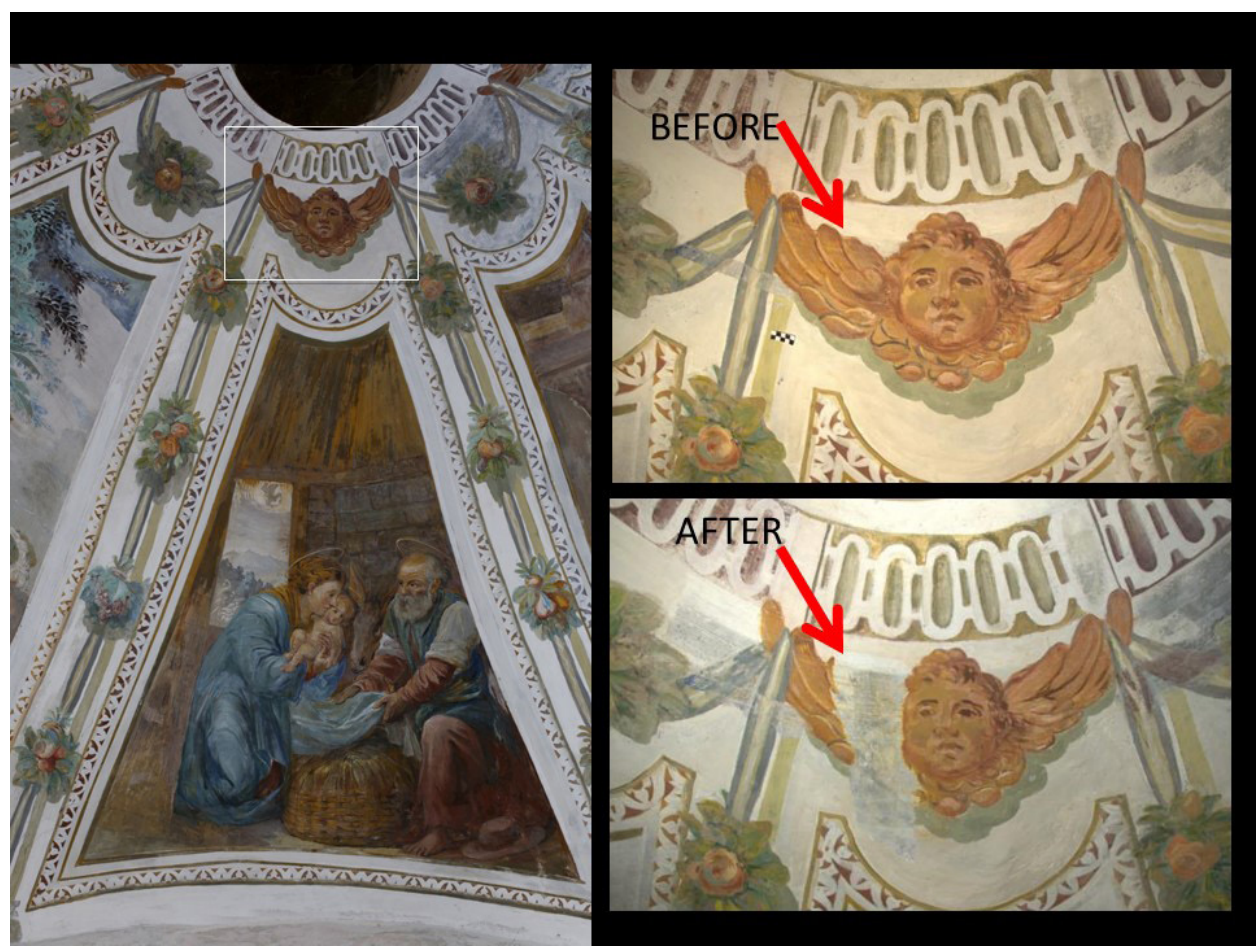

Fig. 6 Overpainting removal test in the architectural portion on the vault. The test revealed that no original paint was present underneath

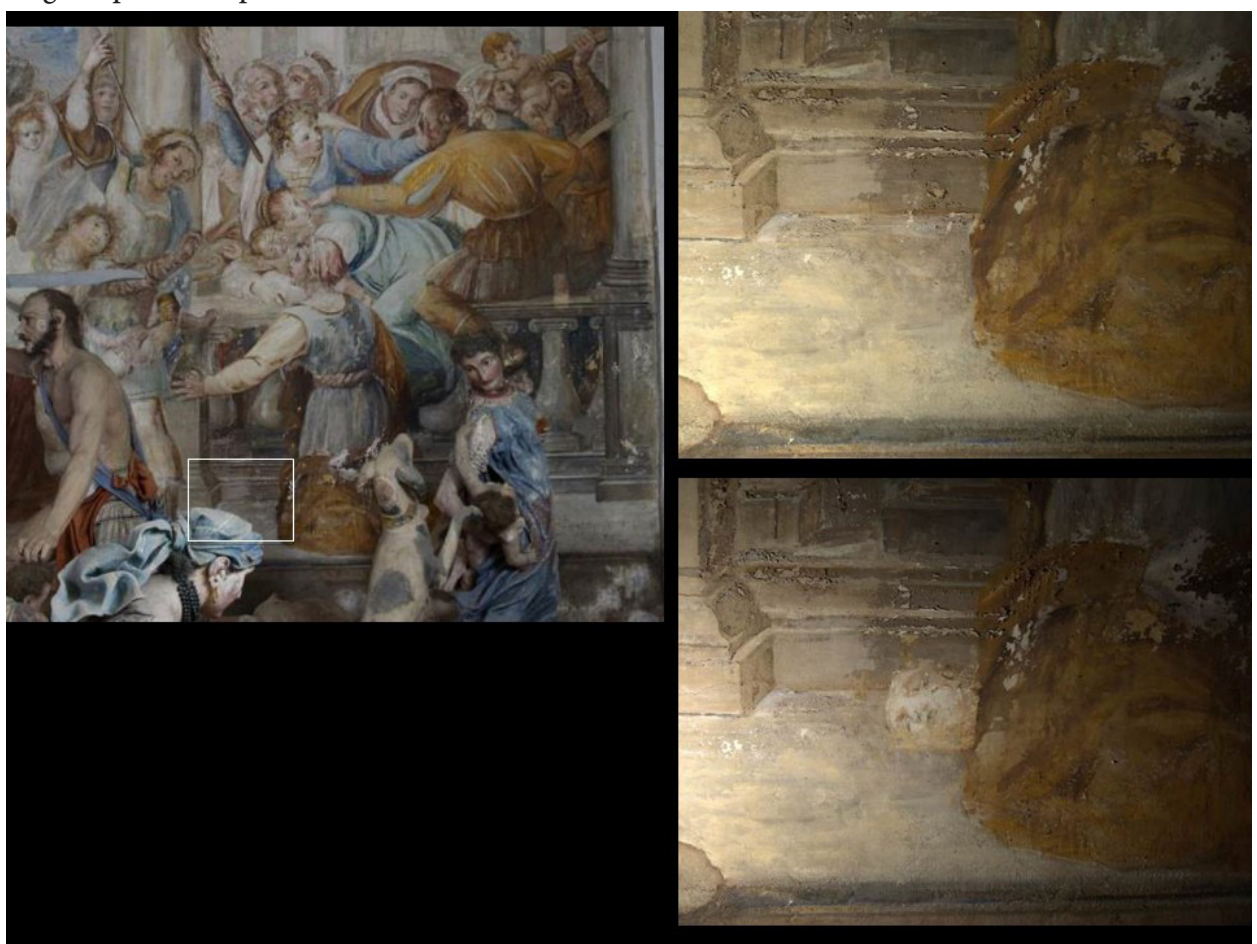

Fig. 7 Overpainting removal test in the architectural portion on the north wall. In this case, the removal of the overpaint revealed the head of a child, which was visible in an historical image 


\section{Extension and value of overpaints}

The investigations showed that the stratigraphic situation varies a lot and that it is not possible to predict how much original is under the repainting and of course in which condition it is. The map in Fig. 8 illustrates in blue the areas in which the recovery of the original layer was considered unpredictable.

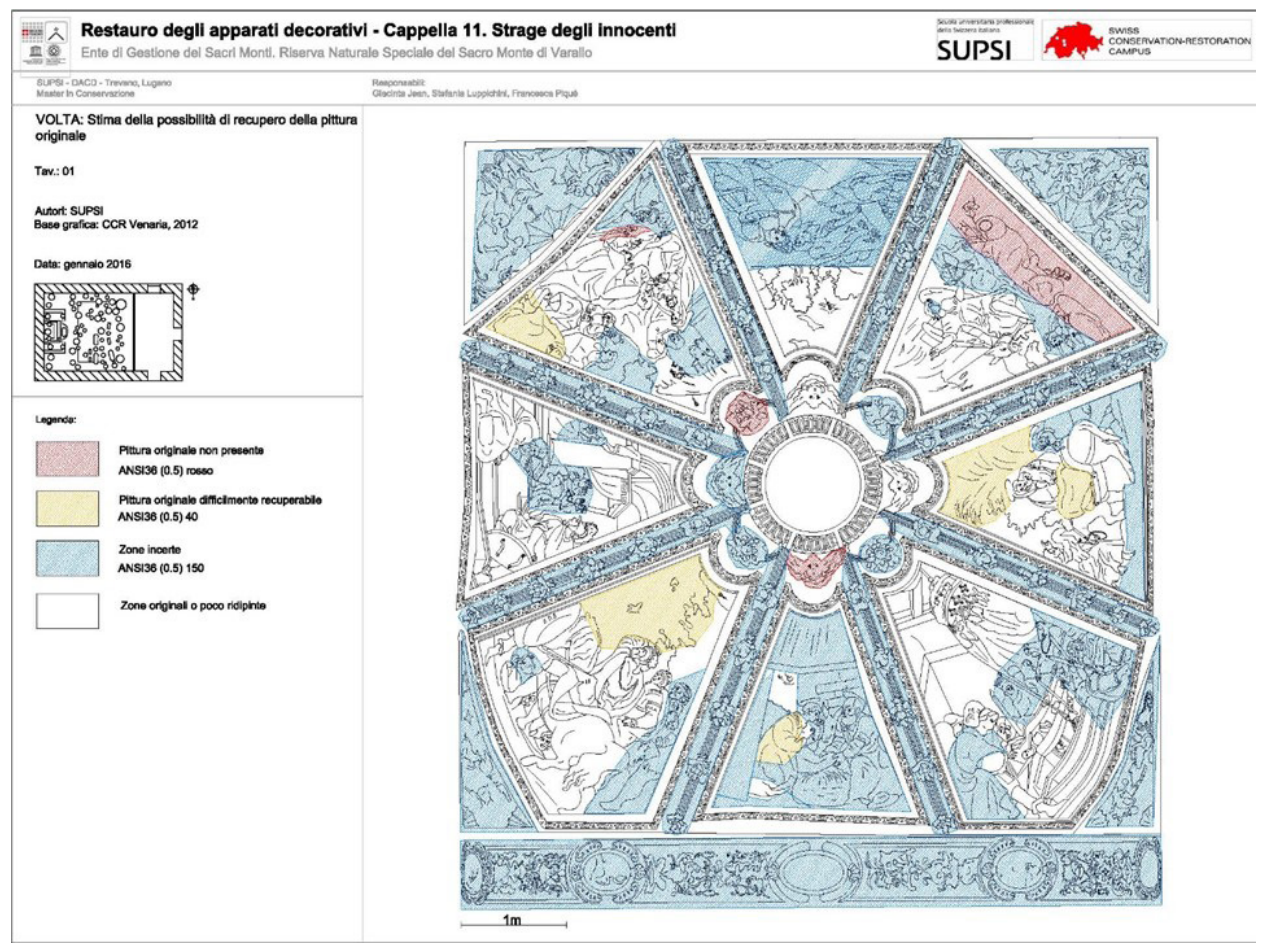

Fig. 8 The thorough examination of the paintings combined with local overpainting removal tests enable the team to summarize the situation in graphic form. The red areas indicate no original paint; yellow indicate areas where the original paint is present, but it is difficult to recover; while the blue indicates the unpredictable areas. The rest, in white, is where the original paint is visible (no repainting is present)

The overpaints modified and disfigured the original, covering it in many places while in others filling and completing areas of loss (i.e. without original paint underneath). Particularly at the base of the walls, around the throne, but also on the vault, large parts of the scenes were missing. These interventions had not the aim of preserving the original. Emilio Contini did not appreciate and respect the work by the Fiamminghini, for him they had no value and could be repainted and completed to give a more appealing look to the chapel, that at the time was in bad repair condition. He also inserted new people and changed the tone of the paintings. It was not a restoration work but a gritty remake and even if over 60-year-old, it is hard to assign to this any significance. 


\section{Removing the overpainting and retrieving the original layers}

The preliminary tests also aimed at evaluating the technical feasibility of removing the overpainting and assessing the effect of the intervention on the original layer. Tests were carried out with different solvents mixtures supported in a gel form. Evaluation was done visually. The removal was easy in areas where the original paint is in a fresco technique, but it was difficult in the area a secco due to the similarity of the painting technique of the ancient and of the new layers. Considering the impossibility to determine the underlying condition and technique of the painting, the removal of overpainting was technically difficult, and it was easy to put the original paintings in danger.

\section{Discussion}

The investigations showed that topographically the situation varies a lot from one point to the other. It is not possible to predict if and how much original is under the overpainting and in which condition it is.

From the technical point of view, it was easy to decide not to remove any of the overpaint. However, it was difficult to take this decision because of the expectations created at the beginning of the project, which is seen by some of the stakeholders as the opportunity to recuperate and disclose the Fiamminghini paintings.

The situation was very complex, with no clear right solution while any option of intervention would put values (artistic, historical, scientific, devotional, didactical ...) in conflict.

In addition, any decision that would have changed the appearance of the wall paintings would had an impact on the statues: the interior decoration is an entire work of art and must be treated as a whole. It was not possible to decide to preserve the actual paint layer on the statues and change the colour tone and increase the number of lacunae on the wall paintings. The religious value of the site has also to be considered (about 60\% of the visitors are coming to the Sacro Monte for pilgrimage, not for visiting an historical monument in which an "archaeological" restoration could have been acceptable).

Discussions rotated around three possibilities:

- preserve the situation as it is (with the overpaints);

- remove all the overpaints;

- remove the overpaints only when covering the original layer and where technically possible.

\section{Preserve the situation as it is}

This option means to preserve a paint layer sometimes unpleasant but over 60 years old and not visible or disturbing from the distance of the viewing grate. In the future, new technologies could provide the possibility to better understand the situation, particularly in term of the presence of underlying original paint layers and make a more informed decision of where - removing the overpaint - the original would emerge (avoiding a casual "scratch and win" approach).

In the meanwhile, to preserve the layers from detaching, methods to stabilize the overpaintings allowing retreatability were developed (Piqué et al., 2017). 


\section{Remove all the overpaints}

Recovering the Fiammenghini would definitively enhance the artistic and aesthetical value of the painting as shown by the successful preliminary tests, where rich and expressive details were revealed. However, this option implies the complete removal of historic layers and it will potentially endanger the original underneath. It would also expose large areas of lacunae, which in turn would require addressing presentation, and the tone of the original paintings would contrast with that of the statues (for which the absence of the original made the question of overpainting removal a mute one).

In addition, with the techniques and materials tested, the removal of the overpainting is a delicate and long operation. The chapel will need extensive retouching after removal of the overpainting. This option will necessarily require large amount of resources (in terms of time and money) that at the moment are not available.

\section{Remove the overpaints only when covering the original layer in good repair condition}

Remove the overpaint when covering the original surface (in good condition) or reduce it on the missing parts was an option difficult to put in practice for three main reasons: first because it was not possible to predict where the original layer was still existing under the overpaints, second because it was not possible to use selective cleaning methods to gradually understand the condition of the original surface and third because it was considered by the conservator-restorers of the team as an arbitrary solution, as each professional would have preserved, removed or reduced a layer according to his/her personal judgment and the intervention would have missed an overall uniform approach, the "unità di metodo".

Laser cleaning using several different instruments was also tested showing encouraging results for its very selective and gradual uncovering. ${ }^{6}$ This intervention however is very expensive and the available budget - generous but not immense - would not be sufficient to cover all the expenses related to this long and complex operation and to all the retouching needed for the final presentation. New founds would have to be provided.

\section{Conclusions}

This project was a first-hand experience of how much changing aesthetic values predominate over other values, especially over the scientific and historic ones. It was difficult to reach agreement, as for many stakeholders the recovering of the artistic value embedded in the Fiammenghini painting was fundamental even if the original painting scheme would have been incomplete, altered and even if removal of overpaint could cause the removal and/or endangering of the original ones.

It is difficult to have a cautious approach when the expectations about the results of a conservationrestoration intervention are to recreate an image corresponding with our contemporary visual culture, removing layers of overpainting that are disturbing and now considered 'the ugly ones'.

During this project emerged the different point of view in assessing the need to remove all or some

6 Laser cleaning tests were carried out by Anna Brunetto. 
of the overpainting, in assessing the technical feasibility of the intervention and, last but not least, in assessing the sustainability of our actions in terms of investments of resources. It was clearly difficult to manage conflicting values and find agreement in the practical application of fundamental conservation principles.

\section{Aknowledgements}

The project was economically supported by the Isabel und Balz Baechi Foundation - providing a grant for a four-year project-, by the Göhner Stiftung - helping to cover the cost of the students working on site - by SUPSI - through the work of its team of teachers - and by the Ente di Gestione Sacri Monti responsible for the safety on site, the works on the building, the final lighting project and for according the use of the guest house for the working team.

In developing the project, we had a strong support from the conservator restorers Stefania Luppichini and Mariangela Santella and from our Master students. We would like to thank all of them for their input and for taking active part in the discussion.

\section{Author Contributions}

This article has been prepared, written and discussed in collaboration by the two authors. 


\section{Bibliography}

Agosti, G. \& Stoppa, J. (Eds.). (2017). Seminario sul manierismo in Lombardia. Milano: Officina Libraria.

Burra Charter (2013). Retrieved July 30th, 2018, from: https://australia.icomos.org/wp-content/ uploads/The-Burra-Charter-2013-Adopted-31.10.2013.pdf.

Caviglioli, L. (1989). Dizionario Biografico degli Italiani, vol. 37. Consulted on http://www.treccani. it/enciclopedia/della-rovere-giovan-battista-detto-il-fiamminghino_\%28Dizionario-Biografico\%29/. De Filippis, E. (2009). Sacro Monte of Varallo. Borgosesia: Tipolitografica di Borgosesia.

Piqué, F., Caroselli, M., Koch Dandolo, C., Luppichini, S. \& Santella, M. (2016). Multitechnical approach for the characterization of the stratigraphy of blue areas in the wall paintings in the Chapel 11 at the "Sacro Monte di Varallo", Italy. International journal of conservation science, Vol 7, Special issues 1, http://www.ijcs.uaic.ro/public/IJCS-16-SI2_14_Pique.pdf.

Piqué, F., Luppichini, S., Acuto, G., Acquistapace, G., De Stefano, A. \& Regazzoni, L. (2017). Can paint stabilization be reversible? The case of the wall paintings in Chapel 11 at the UNESCO site of the Sacro Monte di Varallo. In: J. Bridgland (Ed.), ICOM-CC 18th Triennial Conference Preprints (Art. 1003_451, 8 pages). Copenhagen 4-8 September. Copenhagen: On line publication: https://www.icom-ccpublications-online.org/PublicationList.aspx? search $=\& w g=0 \& v y=$ Copenhagen $+2017 \& t=0 \&$ page $=1$.

Piqué F., Wong, L. \& Boming, S. (2010). Methodology for the Conservation of the Wall Paintings in Cave 85, in Conservation of Ancient Sites on the Silk Road. In: Agnew, N. (Ed.), Proceedings of the Second International Conference on the Conservation of Grotto Sites, Mogao Grottoes (pp.421-429). Los Angeles: www.getty.edu.

Weyer, A., Roig Picazo, P., Pop, D., Cassar, J., Özköse, A., Vallet, J.M. \& Srša, I., (Eds.). (2016 2nd revised digital edition). EwaGlos European illustrated glossary of conservation terms for wall paintings and architectural surfaces. Petersberg: Michael Imhof Verlag GmbH \& Co. KG. Retrieved from http://193.175.110.9/hornemann/doi/2016ewa2a.pdf. 
